\title{
QUANDO AS WEBS SE ENCONTRAM: SOCIAL E SEMÂNTICA - PROMESSA DE UMA VISÃO REALIZADA'?
}

\author{
CUÁNDO LAS WEBS SE ENCUENTRAN: SOCIAL Y SEMÁNTICA - \\ PROMESA DE UNA VISIÓN REALIZADA?
}

\author{
Maria José Vicentini Jorente - mjjorente@yahoo.com.br \\ Doutora em Ciência da Informação pela Universidade Estadual Paulista (UNESP/Marília). \\ Membro do Grupo de Pesquisa - Novas Tecnologias em Informação.
}

Plácida Leopoldina Amorim da Costa Santos - placida@flash.tv.br Professora do Departamento e do Programa de Pós-Graduação em Ciência da Informação da Universidade Estadual Paulista (UNESP/Marília). Líder do Grupo de Pesquisa - Novas Tecnologias em Informação.

\begin{abstract}
Silvana Aparecida Borsetti Gregorio Vidotti - vidott@marilia.unesp.br Professora do Departamento e Coordenadora do Programa de Pós-Graduação em Ciência da Informação da Universidade Estadual Paulista (UNESP/Marília). Vice-Líder do Grupo de Pesquisa - Novas Tecnologias em Informação.
\end{abstract}

\section{Resumo}

A Ciência da Informação solicita definições e redefinições de métodos que valorizem e destaquem os aspectos importantes das relações de disseminação, de recuperação e de compartilhamento de conhecimentos quando ocorre a rearticulação das relações sociais e de produção em torno das Tecnologias de Informação e Comunicação (TICs). Busca-se nas interdisciplinaridades e transdisciplinaridades investigar e dialogar com os diversos campos do conhecimento em rede. Apresenta-se o modelo-teoria de Sáez Vacas (2002) para definir e estudar o Novo Entorno Tecnosocial (N.E.T.) segundo uma perspectiva sistêmica da infra-estrutura digital extremamente complexa, a Rede Universal Digital (R.U.D.) com instrumentos tecnológicos para usuários não técnicos. O momento atual oferece a possibilidade de construção de um saber colaborativo marcado pela inteligência coletiva, em ações sociais de transferência de informação, sob o olhar das redes sociais como um ambiente antropológico de possibilidades. Avanços sociais e tecnológicos criam uma nova dinâmica da Rede e define o aparecimento da Web 2.0, Web Social ou a Web NG (Nova Geração de usuários, os nativos digitais), Web Semântica e Web Social Semântica.

\section{Palavras-chave}

Informação e Tecnologia. Web 2.0. Web Semântica. Web Social. Web Social Semântica.

\footnotetext{
${ }^{1}$ As autoras referem-se à afirmação de Antonio M. Fumero de que a Web 2.0 seria a realização do ideal, das promessas libertárias de acesso universal e livre à informação que os jovens criadores das linguagens de computação e da Internet propagavam no seu início.
} 
O que é evidente e inevitável é que se está produzindo um processo acelerado de impregnação tecnológica de nossas vidas, em que a grande e crescente complexidade da tecnologia e a ainda maior complexidade das relações humanas com ela requerem respostas muito pensadas da índole tecno-cultural, o que não está se dando. Ainda pior, para as que nem sequer existe um mínimo de sensibilidade e de demanda social. Afirmo que, salvo exceções, não estamos preparados para usar com critério nem eficácia a descomunal funcionalidade da tecnologia que passa por nossas mãos, nem para compreender o Novo Entorno Tecnossocial - NET e muito menos para administrá-lo convenientemente e extrair o melhor de suas extraordinárias oportunidades informativas, de comunicação, artísticas, científicas, de entretenimento, sanitárias e operativas de muitas espécies, também educativas mas sem renunciar ao que mereça conservar-se.

\section{Fernando Sáez Vacas}

As evidentes e propagadas transformações econômicas e sociais da segunda metade do século XX e dos primeiros anos do século XXI tornam necessário elaborar ensaios de compreensão em estudos científicos contemporâneos que as situem neste contexto histórico e possam criar os caminhos para pensá-las.

Nos atuais anos da globalização, termo usado para designar um

[...] conjunto de ideias sobre uma nova forma de relacionamento internacional entre os governos, as empresas e os indivíduos; um conjunto de fatores, com elementos para a intensificação do comércio internacional de produtos e serviços, do intercâmbio cultural acentuado e de modo muito especial, do trânsito e da fluidez das informações. (SANTOS; VIDOTTI, 2009, p.7).

Neste cenário, [...] "um dos principais desafios da Ciência da Informação é transformar a massa de dados operacionais disponíveis diariamente em informações consistentes que permitam a tomada de decisões e agreguem valor às atividades" (SANTOS; VIDOTTI, 2009, p.7). Nossa percepção é a de que, se no processo de transformação ocorre a rearticulação das relações sociais e de produção em torno de Tecnologias de Informação e Comunicação,

[...] a Ciência da Informação deveria ter ou criar mais espaços de investigação que permitam a compreensão das Tecnologias de Informação e Comunicação (TICs) para a potencialização de competências informacionais, para a criação de arquiteturas informacionais e computacionais mais inclusivas, para a conceituação de usos da informação em ambientes informacionais digitais, para a aprendizagem de metalinguagens e para a representação da informação. (SANTOS, VIDOTTI, 2009, p. 5) 
Neste sentido, buscamos, com ênfase em interdisciplinaridades e transdisciplinaridades, investigar e dialogar com os diversos campos do conhecimento, que com o reposicionamento de seus centros no humano, tratam da sua presença na trama complexa das relações em rede. Estas não são identificadas com um líder ou centro organizador fixo, mas em interações dos ambientes informacionais digitais, com sujeitos psicossociais autônomos conectados, bem como, e as riquezas informacionais que constituem estas relações. A difusão das idéias, a existência das coisas, a criação de opiniões, o sentido que o homem dá a sua existência são construtores da realidade social marcada pela capacidade de ação e de interação para alcançar objetivos e interesses que dão sentido à existência e ao desenvolvimento humano nas relações cotidianas.

Considerando que a Ciência da Informação, como área do conhecimento que se consolida e se legitima no contexto da sociedade contemporânea, solicita definições e redefinições de métodos que valorizem e destaquem os aspectos importantes da relação de disseminação, recuperação e compartilhamento de informações e conhecimentos, empreendemos nesta direção o atual estudo.

Adotamos, em nossas propostas de estudo e trabalho, a visão de desenvolvimento segundo o economista chileno Max Neef (2003), a qual tem a ver com pessoas e não com objetos: o melhor desenvolvimento é aquele em que a qualidade de vida das pessoas mais cresce. Isso depende das possibilidades que elas têm, ou não, de adequadamente satisfazer suas necessidades humanas básicas. Neef aponta ainda que as necessidades básicas (ser, ter, fazer, interagir, subsistência, proteção, afeto, participação, compreensão, ócio, criação, identidade e liberdade) não mudam; o que muda são as coisas que as sociedades geram para satisfazer tais necessidades ou para incrementar a sensação de novas necessidades.

Para Fernando Sáez Vacas que, em Sociotecnologia da Informação, assume esta mesma visão e propõe como necessárias uma hibridez e uma redefinição entre as áreas de engenharia e humanidades, as tecnologias da informação compreendem o conjunto formado pelas telecomunicações e a informática, com todos os seus antecedentes e consequentes (microeletrônica, redes de computadores, groupware, rede Internet, tecnologias de multimídia etc.): "conjunto que, como infraestrutura crescente em tamanho e capilaridade tendente à ubiquidade, acabou denominando, a partir de agosto de 1999, Red Universal Digital (R.U.D)" (SÁEZ VACAS, 2008, p.2, tradução nossa). 
Segundo o autor, a apresentação de uma Rede Universal Digital se projeta na arquitetura do ciberespaço como um imenso tecido de redes: - wan, lan, san, han, ban ou pan - em que estarão conectados todos os tipos de plataformas informáticas, por meio de interfaces e de sensores com o mundo natural das pessoas, das coisas e dos fenômenos físicos, compreendida em algo mais que comunicação; é percepção, pensamento, representação e controle, o embrião de um sistema nervoso universal completo.

Algumas das plataformas informáticas previstas para construir essa arquitetura ciberespacial são: a) Multicomputadores escaláveis: coleções de computadores independentes de tipo standard, controlados por sistemas operacionais distribuídos e ligados por redes para realizar grandes cálculos e operações de serviço em Intranets; b) Chipscomputadores completos, especializados para certas aplicações; c) computadores ubíquos, ocultos dentro das coisas, das paredes, das roupas, dos eletrodomésticos, de livros, dos corpos, dos carros e conectados por redes com todos os seus congêneres digitais. (SÁEZ VACAS, 2004, p.2, tradução nossa).

Sáez Vacas constrói assim o modelo-teoria para definir e estudar o Novo Entorno Tecnossocial (NET), segundo uma "visão geral sistêmica da infraestrutura digital extremamente complexa, progressivamente reticular, com uma porcentagem cada vez maior de instrumentos tecnológicos para usuários não técnicos" (SÁEZ VACAS, 2008, p.12, tradução nossa). De acordo com esta visão, a vida cotidiana está permeada por subconjuntos de tecnologias constituintes de um conjunto maior e heterogêneo em constante evolução. Este, composto por subsistemas e redes múltiplas, caminha para convergência e interoperabilidade: a RUD

[...] não é uma rede concreta, mas sim um conjunto heterogêneo em plena evolução, composto por múltiplas e diferentes redes: Internet, rede informáticas de área local, redes telefônicas fixas, redes de telefonia celular, redes $\mathrm{Wi}-\mathrm{Fi}$, redes de satélites GPS, redes de energia elétrica com tecnologia PLC, redes corporativas (ban: body area networks), redes de sistema (em um automóvel, por exemplo), Internet 0 (Internet das coisas), redes de circuitos fechados de TV, etc., cada dia mais digitais (incluíndo rádio e televisão) e interoperáveis. Um imenso tecido de redes, complexo e quase invisível, no qual pode observar-se a repetição quase fractal de uma arquitetura básica. Distintas plataformas (computador, microprocessador, pda, televisão, telefone, reprodutor de música, console de jogos, sensor, etc.) se conectam ou podem conecta-se a uma rede e esta a outra ou outras. (SÁEZ VACAS, 2007, p.107-108).

Para o autor, muito além das etiquetas (referência provável à folksonomia, o aspecto mais evidenciado da Web Social), a forma de se conceber a Rede foi completamente alterada com a aparição de tecnologias que propiciaram uma mudança radical nas rotinas com que nos equipávamos na hora de navegar. 
Tendo claro que o importante são os efeitos sobre as formas sociais, as atividades e comportamentos humanos de variados tipos, o autor propõe que 0 estudo e formalização do entorno gerado por essas tecnologias se constitua em assunto vital para a contemporaneidade: um campo que ele denomina de Sociotecnologia da Informação. Neste novo campo é criado o conceito de Netoscópio(NR), com 21 dimensões distribuídas nas 5 categorias que a seguir se citam. Nele se indicam variáveis com que se possa compreender e focar os efeitos da R.U.D, e seus diferentes impactos no entorno contemporâneo (SÁEZ VACAS, 2007):

\section{Transformações na representação, na captação e no manejo de informação (4 dimensões):}

- Digitalidade: o "alfabeto" binário, construído somente por dois símbolos (0 e 1) é a verdadeira linguagem universal das máquinas que forma a trama infotecnológica da rede;

- Potencialidade: as infotecnologias mostram-se como ambientes para a construção de uma realidade que nunca se mostra realizada por completo. Com elas se tem a ampliação constante da capacidade de armazenamento e da velocidade dos processadores, o crescimento das redes de comunicação, o surgimento de novas funcionalidades e a implementação de serviços inovadores;

- Oniprocessabilidade; capacidade de processamento estendido por todos os nós da infraestrutura: telefones móveis, pontos de acesso Wi-Fi, sensores, implantes médicos, etc.;

- Análogo-digitalidade: a fronteira entre os mundos real e digital está cada vez mais imperceptível, especialmente para os nativos digitais.

\section{Transformações espaço-temporais (5 dimensões):}

- Instantaneidade: a velocidade e a imediatez são esperadas em todas as interações;

- Distalidade: a ação/comunicação à distância é uma propriedade específica das telecomunicações e essa característica condiciona ações e cria novas possibilidades; 
- Ubiquidade: em todas as partes e em nenhuma; não há uma "localização" específica, mas se pode acessar de qualquer localização geográfica;

- Mobilidade: característica catalisadora de mudanças sociais derivadas dos novos usos e costumes na Sociedade da Informação;

- Reticularidade: novas possibilidades de comunicação e ação global, uma nova geração de comunidades virtuais; as organizações buscam na moderna teoria de rede 0 instrumento para desmontar as hierarquias.

Transformações corporais, sensoriais, relacionais, nas fronteiras da ação pessoal e identidade (6 dimensões):

- Representabilidade: relacionada como a distalidade, pois muitas entidades nos representam para realizar ações à distância, por exemplo, o Second Life e os agentes inteligentes que tomam decisões por nós;

- Protesicidade: no período de convergência tecnológica as infotecnologias se integram aos dispositivos nanotecnológicos e biológicos para estender as possibilidades próprias do corpo humano. Desde implantes de membros biônicos até a consideração da Internet como um sistema nervoso global; um suporte de memória coletiva e de uma inteligência planetária;

- Multissensorialidade: o acesso generalizado à banda larga e às redes de sensores miniaturizados pela nanotecnologia que domina a indústria eletrônica e/ou os avanços realizados na moderna ciência dos materiais oferecem muitas promessas com realizações práticas e avançadas, como é o exemplo das próteses sensoriais;

- Interatividade: entre homem-homem, homem-máquina, máquina-máquina;

- Virtualidade: mais do que uma realidade virtual, uma virtualidade muito real; como exemplo, o dinheiro que flui [virtualmente] pelos circuitos financeiros globais de forma absolutamente virtual;

- Rastreabilidade: todas as ações deixam rastros, são rastreáveis para os que têm a intenção, os conhecimentos e os recursos. 


\section{Transformações funcionais da infraestrutura infotecnológica (2 dimensões):}

- Neuralidade: na Internet se podem associar os hiperlinks às sinapses neurais, como metáfora da completa rede de conexões que determina a estrutura neural de uma espécie de cérebro planetário, global;

- Intelectividade - uma espécie de inteligência coletiva.

\section{Barreiras que se contrapõem (4 dimensões):}

- Intangibilidade: invisibilidade e complexidade da inteligência tecnológica que sustenta a rede digital e que passa despercebida ao usuário que a ela se conecta. Duplamente invisível, porque os circuitos, as ondas, o software, as senhas, são imperceptíveis aos sentidos humanos e também por sua complexidade, pois seus mecanismos são incompreensíveis, a não ser para os técnicos; as interfaces operacionais para os usuários são adaptadas a realidade operacional de funcionamento;

- Hermeticidade: a própria tecnologia se mostra como um domínio de difícil acesso para o usuário não especialista;

- Descontinuidade: instantânea gerada pelos fluxos de informação e sua representação e também uma descontinuidade relativa à obsolescência dos formatos de representação da informação e dos suportes de armazenamento permanente;

- Feudalidade/Domínio: os novos senhores feudais (os domínios na rede), têm a seu serviço um infocidadão leigo que rende servilidade no consumo de massas do que aparece digitalizado numa dissimulação de autoridade no Novo Entorno Tecnossocial.

Como Sáez Vacas (2004) enfatiza, por trás de todos estes enfoques há um conceito-chave que é a Coevolução entre Humanidade-Tecnologia; um fato que, devido ao crescente grau de especialização das sociedades em que se presentifica o fenômeno, tendemos a esquecer ou simplesmente desconhecemos. $\mathrm{O}$ autor afirma também que a Rede Universal, nela a Web e principalmente a blogosfera, assiste ao nascimento de uma nova formação de inteligência, que ele denomina noomorfosis digital (do grego noos=inteligência, morphosis=formação). 
A noomorfosis digital é identificada como um fenômeno transcendental ainda imperceptível como um todo, mas já aparente em diversas situações que envolvem um número crescente de "nativos digitais": aqueles que já nasceram imersos sob estas novas formas de criação e disseminação da informação, contidas pela RUD.

Não se trata de que o uso intensivo da tecnologia da R.U.D. contribua para moldar uma inteligência maior ou menor - por exemplo que as crianças sejam mais prontas, como alguns dizem -, e sim de uma inteligência funcionalmente distinta, ou seja, armada com certas capacidades necessárias especialmente desenvolvidas para viver e operar no Novo Entorno Tecnossocial (N.E.T.) gerado por esta tecnologia. (SÁEZ VACAS, 2006, p.2, tradução nossa).

A interação e os relacionamentos têm a comunicação e a informação como fundamentos para a existência de um processo de troca de experiências e transformação, pois a falta de informação geralmente condena as comunidades a uma espécie de medo coletivo para agir e construir futuros (JARA, 1998).

O acesso e o uso da informação, todavia, geram o poder de organização e propulsionam o desenvolvimento e ações criadoras promovendo o "empoderamento" individual e coletivo das pessoas envolvidas na vida comunitária. Empoderamento é a potencialização das comunidades e dos indivíduos por meio da educação, da informação e da comunicação, para que as pessoas possam controlar suas próprias vidas de modo a ter a possibilidade de interferir na construção de seu futuro (SANTOS, 2008).

Por outro lado, formas sociais emergentes e declinantes determinam estruturas mentais distintas com matrizes de inteligência e comportamento formadas quando as "crianças constroem conceitos de espaço, tempo, número, causalidade, identidade, memória, vida e mente, e o fazem precisamente a partir dos objetos que as rodeiam". Neste sentido, Sáez Vacas acrescenta que os nativos digitais, habitantes da infocidade, ganharão em todas as capacidades relativas aos seus processos imateriais típicos (2006, p.3) A infocidade será então:

Espaço informacional em que os humanos de sociedades desenvolvidas, mediante terminais com botões, teclas, telas, contra senhas e identificadores, se comunicam e realizam uma parte crescente de suas atividades habituais e muitas outras novas, convertidas em sinais, símbolos, linguagens e processos imateriais, suportados por uma potente infraestrutura tecnológica de arquitetura reticular. (tradução nossa).

No entanto, o próprio autor afirma sem ingenuidade que, "à medida que a vida vai sendo substituída pela informação, já estão se perdendo e se perderão mais outras 
capacidades e habilidades que foram consideradas valiosas até agora" (2006, p.3). Por essa razão, propõe uma cartografia das mentes desenvolvidas pela R.U.D. e relaciona a necessidade à proposta de Antonio Fumero de separar as questões a ela relativas em dois níveis, o da Nova Estrutura Neural (ou NEN, o nível do cérebro) e o do Novo Esquema Psicossocial (NEP, o nível mental).

A natureza conceitual da Rede Universal Digital proposta por Sáez Vacas é a de convergir paulatinamente na interface com o ser humano para perceber, conhecer, registrar e organizar o mundo por meio da informação. A informação é, portanto, a peça fundamental no desenvolvimento das atividades humanas. O conhecimento de seu fluxo, a percepção do ambiente informacional, a destreza no manuseio e no uso de recursos tecnológicos que favoreçam o acesso, o tratamento, a recuperação e o (re)uso de informações facilitam a geração de novos conhecimentos.

A presença da tecnologia no cotidiano das pessoas formando opinião, criando necessidades e determinando comportamentos torna a investigação dessa temática na Ciência da Informação extremamente importante no processo de formação reflexiva dos sujeitos no que se refere ao uso de recursos informacionais alocados nos mais diversos suportes e ambientes. É investigação importante também no favorecimento das estratégias do empoderamento enquanto ação coletiva desenvolvida pelos indivíduos quando participam de espaços privilegiados de decisões e de consciência social dos direitos sociais.

\section{O imperativo das redes}

O cenário sócio-político-econômico atual contempla, entre seus constituintes, sujeitos pós-modernos inseridos em uma rede que abrange a formação de conhecimentos a partir das relações sociais, como uma teia de relações que não se inicia em uma estrutura linear. Neste sentido, é fundamental a articulação entre a idéia de rede e os processos de produção, de tratamento, de difusão, de recuperação e de (re)uso do conhecimento para o empoderamento.

Por outro lado, é imprescindível a percepção de redes informacionais estruturadas como modelos de ambientes colaborativos de inteligência coletiva como favorecedoras do fortalecimento das competências, da confiança e da capacidade humana.

A ideia elementar de rede se origina do latim rete, com significado de entrelaçamento de fios com aberturas regulares que formam uma espécie de tecido, uma 
malha de estrutura reticulada que pressupõe flexibilidade, conectividade e descentralização. As redes, como sistemas organizacionais, propiciam a reunião de indivíduos e instituições em torno de objetivos comuns e elas se estabelecem por relações horizontais, interconexas e em dinâmicas que supõem o trabalho colaborativo e participativo estabelecido de forma orgânica. Nelas, a convivência entre os integrantes e o estabelecimento de laços de afinidade serão definidos a partir de pactos sociais ou padrões de relacionamento.

Com base no que se pode depreender dos apontamentos dos autores Wersig e Windel 1985; Belkin 1990, Deleuze 1988, Habermas 1993 e González de Gómez 1995, a Ciência da Informação lida especialmente com atores em diferentes graus de complexidade e que requerem a provisão externa de argumentos de racionalização na superação do individualismo psicológico e a incorporação da atual sociabilidade a partir das tecnologias de informação e comunicação.

O momento atual oferece a possibilidade de caminhar pela construção de um saber colaborativo marcado pela inteligência coletiva, em ações sociais de apropriação da informação, com o olhar para as redes sociais como ambiente antropológico de possibilidades. A apropriação da informação presume a existência de um valor da informação partilhado pelos participantes. Aponta-se neste aspecto que as ações sociais de transferência da informação requisitam a utilização de procedimentos técnicos, expressivos ou normativos de dimensões cognitivas e comunicacionais no contexto de formação e preservação de memórias e na socialização do conhecimento. As condições pragmáticas de aceitação e reconhecimento do valor da informação são dimensões do sucesso das ações de transferência de informação com ênfase no conceito de relação intrínseco na teoria social de redes.

Uma rede social é uma estrutura social interconectada por um conjunto de nós (individuais ou grupais) que são interligados por um ou mais tipos de relacionamentos. A rede tem a informação como operador da relação nas estruturas sociais; e também nos aparatos tecnológicos informacionais da transferência (ambientes digitais, estruturas de produção, tratamento, armazenamento e reprodução de recursos ou mensagens, produção de novos sistemas e modelos de armazenagem e acesso à informação, entre outros).

Reed et al. (2004, p.1) em "Web social: Criando uma rede social aberta com XDI" propõem um Imperativo das Redes, o qual determina que, à medida que novas 
tecnologias de comunicação se desenvolvem, novas redes de comunicação são criadas, com constante evolução e aceleração. Isto pode ser percebido nos 1930 com o surgimento do telefone, nos $1970 \mathrm{com}$ o fax, nos $1980 \mathrm{com}$ a Internet e o e-mail, e nos 1990 com as redes sem fio, as mensagens instantâneas e a Web: novas capacidades foram progressivamente adquiridas pelos sistemas de redes: "[...] mais informação para dividir, em formatos mais ricos, sustentados por mais canais, com mais envolvimento de usuários, em maiores velocidades." (2004, p.1).

Uma breve incursão na história do termo destaca que o termo Web (Rede) Social foi introduzido em 1955 por August C. Krey em ensaio publicado pela editora da Universidade de Minnesota. Nos anos 1990, uma crescente onda de utilização dos conceitos ligados ao bem-estar social, entre eles aqueles relacionados à Internet, alimentam entusiastas de um mundo sem fronteiras, inspirados no livro emblemático de Beneditc Anderson, "Comunidades Imaginárias" (em que se descreve uma nação como uma comunidade imaginária construída principalmente baseada na mídia).

As preocupações com a efetiva socialização da Web, porém, começam a aparecer a partir da percepção de sua crescente privatização nos anos imediatamente posteriores ao seu lançamento no mercado. É, já em 1987, o que demonstra a publicação de Hypertext Publishing and the Evolution of Knowledge de Eric Drexler (ele trabalhou com T. Nelson nas questões do Hipertexto, como originalmente concebido por este), cobrava um software realmente social.

Peter Hoschka $(1998)^{2}$ reutilizou o termo Web Social para descrever a percepção da evolução do conceito de computadores e da Web como ferramenta de cooperação. $O$ desenvolvimento desta percepção 'elevou-os' ao status de meio social, no sentido de que o meio é a mensagem, como Marshall McLuhan (1974) emprega em "Os meios de comunicação como extensões do homem). Hoschka (1998, p.6) comenta que a cooperação suportava a funcionalidade e se tornava, então, crescente fator de desenvolvimento de sistemas operacionais abertos e em parceria; porém muito pouco estava sendo desenvolvido no âmbito das organizações de pesquisa, razão pela qual o foco de seu trabalho de pesquisa passou a ser o computador como um meio social:

\footnotetext{
${ }^{2}$ Pesquisador do Institute for Applied Information Technology (FIT) - GMD German National Research Center for Information Technology.
} 
[...] os computadores e as redes estão começando a formar espaços sociais em que as pessoas se apresentam, encontram outras pessoas, trocam notícias, jogam, realizam negócios ou conjuntamente procuram informação. Uma nova forma de espaço de ação e interação está emergindo. Computadores e redes estão se desenvolvendo em um meio social e formando uma nova espécie de habitat. (tradução nossa).

Hoschka adiciona ainda que este espaço não é somente composto de informação (como no passado), mas que é cada vez mais ocupado por pessoas que estão por trás desta informação. Pessoas que se tornam reconhecíveis como sujeitos. De acordo com sua visão, no futuro o espaço virtual hospedará um número exponencialmente "[...] crescente de agentes de softwares que procuram por certas tarefas e realizam funções em benefício de seus clientes. Assim, no futuro, a rede será 'povoada' e 'habitada'-por pessoas bem como por agentes." (1998, p.6, tradução nossa).

Em 2002, o Social Software Summit em Nova York também enfatizava a necessidade de um software construído e constituído por ferramentas que facilitassem a interação e a colaboração grupal. Tal software foi definido sob as condições de dar suporte à interação conversacional entre indivíduos e grupos, abrindo espaços de colaboração, realimentação social, criando redes sociais gestoras do conhecimento, e que oferecessem a este a necessária reputação digital. Criou-se a partir de avanços sociais e tecnológicos uma nova dinâmica da Rede, uma confluência que definiu a o aparecimento da Web 2.0, aceita pela maioria dos teóricos como a Web Social ou a Web NG (NG refere-se à nova geração de usuários, os nativos digitais, que trafegam na rede). Shirky (2003), o responsável pela organização do evento, define o social software como um programa que apoia as comunicações em grupo, buscando interoperabilidade entre sistemas e incluindo os mais variados serviços. Entre eles se destacam o e-mail, os mundos virtuais em três dimensões (3D), as salas de bate-papo e as ferramentas wiki, como a Wikipédia, a enciclopédia livre, editada de forma colaborativa e mantida pela Wikimedia Foundation.

Se a interoperabilidade é um elemento chave no processo de comunicação entre indivíduos e sistemas, o XDI (XRI Data Interchange) é essencial para a interoperabilidade, e é um elemento tecnológico propiciador da Web Social. O protocolo XDI de distribuição e compartilhamento de dados possibilita uma nova camada de aplicação confiável para intercâmbio de dados; o serviço XDI automatiza o compartilhamento, a descrição, a linkagem e a sincronização de dados de qualquer tipo na Internet e em outras redes de dados, utilizando documentos XML (Extensive Markup Language) e XRIs (Extensive 
Resource Identifiers); e o dicionário XDI especifica com semântica. Segundo a Organização para o Avanço dos padrões da Informação Estruturada (Organization for the Advancement of Structured Information Standards - OASIS, 2006, p.1):

O objetivo do XDI, entretanto, é possibilitar o intercâmbio automático de qualquer tipo de dados, muito à maneira que as linguagens humanas possibilitam a discussão de qualquer tipo de assunto. Para fazê-lo atendendo às diferentes necessidades das comunidades, o XDI requer a mesma ferramenta de compartilhamento de vocabulário usada pelas línguas humanas: dicionários. Um dicionário $D$ atawe $^{3}$ é simplesmente uma coleção de páginas de Dataweb usadas para definir e descrever os dados XDI que podem ser divididos pelos assinantes daquele dicionário. (tradução nossa).

Foi este mesmo conceito de interoperalidade que intelectuais, aplicadores e companhias de negócios reforçaram, na Conferência Web 2.0, hospedada por Tim O'Reilly, John Battelle e MediaLive, em 2004. Desde então, é sobre ele que se insiste como a base da própria Web 2.0: um mundo em que todas as redes sejam interoperáveis. Os sites/serviços GMail, BitTorrent, Del.icio.us, FlickR e YouTube possuidores dessa característica de interoperabilidade tornaram-se a nova encarnação da Nova Internet: a Web 2.0 congrega uma série de princípios que definem este tipo de serviço integrado, em que os programas rodam na própria Internet, nos super servidores das companhias.

Em 2004, recém-cunhado o conceito Web 2.0, Tim O’Reilly, um verdadeiro guru dos negócios na Web Social, já afirmava que, doravante, a Web seria o centro de tudo, e que nela as regras seriam diferentes, implicando com isto uma nova virada no poder: "[...] uma filosofia de participação e compartilhamento e um sentido de ação coletiva que inevitavelmente conduzirá para o bem maior." (O'REILLY apud LEVY, 2005, p.2). mesmo O'Reilly é o detector das tendências que o fizeram tornar-se um dos fundadores do Blogger, comprado pela Google, e um investidor no serviço de compartilhamento deli.cio.us.

Não são, porém, somente os serviços oferecidos pela plataforma, como o Google, o Yahoo ou o Flickr, mas as próprias modelações das estruturas subjacentes a estes serviços as possibilitadoras de tamanha pervasividade (deixando ao usuário somente a interface web como produto final visível e operável) que estão em convergência. Conforme explicita Fumero, é uma aproximação nova da filosofia de desenho de software

\footnotetext{
${ }^{3}$ O Dataweb combina os princípios chave da arquitetura com os conceitos principais dos serviços da Web e Web Semântica em uma solução que pode ser "a simplicidade no outro lado da complexidade" para compartilhamento de dados distribuídos.

http://www.oasis-open.org/committees/download.php/5115/wd-xdi-intro-white-paper-2004-01-20.pdf
} 
que estende o conceito de hipertexto às aplicações e aos serviços na Rede que utiliza os recursos, os nós e os enlaces a eles como metáforas, pois:

Os sistemas de gestão de conteúdo (Content Management Systems, CMS) constituem os alicerces essenciais das plataformas de prestação de serviços de publicação e colaboração apoiados em blogs e wikis. (FUMERO; ROCA, 2007, p.15, tradução nossa).

Como comenta Fumero, a metáfora da Web é ampliada ao próprio design das aplicações; quando fazemos referência a qualquer uma destas ferramentas de colaboração, comunicação e expressão, devemos saber que por trás há sistemas técnicos de certa complexidade, que são parte desta infraestrutura invisível que se confunde com a tessitura da RUD.

O autor aponta que no desenho e na arquitetura de sistemas, a REST (Representational Status Transfer) ${ }^{4}$ significa voltar às origens da Rede como foi proposta por Tim Bernes-Lee:

[...] tendência que aporta elementos tecnológicos para a construção de arquiteturas de sistemas que suportem o crescimento de uma Web mais social, mais interativa e, com muitos matizes, também mais participativa e pode ter sua adoção na interoperabilidade entre serviços na Web. (FUMERO; ROCA, 2007, p. 15-16).

Levando-se em consideração os aspectos de interação das Ciências Cognitivas, da Computação e outras na utilização das interfaces da Web Social, proporcionam-se as oportunidades de se pensar variadas questões relativas aos usuários:

[...] como um universo maior do que aquele que compreende os que sabem associar um RSS ao seu blog. Se a tecnologia que permite as novas ferramentas deve ser extremamente amigável e acessível, como a do permalink, será necessário saber o que permite agregar comentários, publicar opiniões e fazer proliferar as conversas entre as comunidades de usuários de maneira invisível? Que adicionar um comentário a um blog de que se recebeu um RSS de atualização combina dois protocolos distintos? Ou não? Atravessa-se a ponte criada para a transmissão dos conteúdos e se obtém a satisfação imediata? (JORENTE, 2009, p.188).

Nesse sentido, muito se tem falado da Web Social e da auto-organização da informação ultimamente; até porque a tríplice convergência entre as tecnologias do

\footnotetext{
${ }^{4}$ [...] o Representational State Transfer (REST) é um estilo arquitetural para sistemas hipermídia distribuídos. REST oferece um conjunto de regras arquitetônicas que, quando aplicadas como um conjunto enfatiza a escalabilidade das interações dos componentes, generalidade de interfaces, desenvolvimento independente de componentes e componentes intermediários para reduzir latência de interações, reforça segurança, e encapsula os sistemas legais. Fielding (2000, p.105).
} 
pequeno (ou nanotecnologia), do vivo (ou biotecnologia), e do conhecimento (ou neurociências e ciências da cognição) é impulsionada por novas visões do próprio conceito de tecnologia. Esta deve ser, se não compreendida, ainda assim operada pelo ser humano, a quem deve servir (FUMERO, 2007). O fenômeno mundial denominado convergência NBIC (Nano-Bio-Info-Cogno) irá regular progressivamente a informação entre os variados setores do humano, desde aqueles que envolvem os imigrados até nativos digitais, sobre os quais o crescente impacto ainda está por ser estudado e administrado.

\section{Estado da arte}

O que se verifica em 2009 é que, com o rápido desenvolvimento dos conceitos que os termos Web 2.0 e Web Social trazem embutidos, estes já foram absorvidos por produtos gerados comercialmente, profissionalizando também tal aspecto da rede. $O$ MySpace e o YouTube foram, por exemplo, invadidos por relações públicas e propaganda. Todo o conceito de Web 2.0, enfim, foi tomado por profissionais que reformulam a, uma vez dominante, mídia profissional, provocando um intercâmbio criativo e muito rentável.

Companhias como a Telefónica espanhola têm se envolvido em projetos com as principais Universidades da Espanha para discussão e esclarecimento. Usam o próprio sistema, a plataforma Web principalmente, para colocar em pauta e divulgar aos interessados não especializados os resultados, como é o caso do projeto "Creamos el futuro"

[...] Vivemos imersos em uma espiral de mudança que trouxe consigo a Sociedade da Informação e do Conhecimento, que faz difícil imaginar como será o desenvolvimento econômico-social e como ela impactará nas formas de viver e de relacionar-se. As novas áreas científicas relacionadas com a Biologia e a Nano-tecnologia junto com as Ciências Cognitivas fazem prever mudanças radicais. [...] Por este motivo, com uma vocação integradora de opiniões, a Telefónica criou a plataforma de debate Criamos o Futuro instrumentada com ferramentas de trabalho em Rede para que os investigadores, estudiosos e analistas dos impactos tecnológicos possam intercambiar opiniões entre si e comunicar-se com as pessoas que têm inquietude por conhecer como será a Sociedade do futuro. (tradução nossa).

\footnotetext{
${ }^{5} \mathrm{http}: / /$ blogs.creamoselfuturo.com/tecnologia-del-conocimiento/a-cerca-de-creamos-el-futuro/
} 
Esta e outras ações empresariais, que buscam aliar-se às pesquisas acadêmicas na área, demonstram que o conceito Web Social vai muito além dos aspectos de comunicação interpessoal revolucionada pela combinação de microformatos na nova estrutura tecnológica proposta pela Web 2.0. Ou seja, vai além das implicações da convergência tecnológica no presente da Sociedade da Informação. Busca moldar um mundo futuro com implicações coletivas e sociais, como o conceito de noomorfosis digital de Sáez Vacas faz entrever.

Por outro lado, críticos como Nicholas Carr, anteriormente editor executivo do Harvard Business Review, escrevem e falam sobre tecnologia, negócios e cultura. Em Does IT Matter? Information Technology and the Corrosion of Competitive Advantage, (Importa? Tecnologia da Informação e a corrosão da vantagem competitiva) publicado pela Harvard Business School Press, de 2004 e em The Big Switch: Rewiring the World, from Edison to Google, (A grande virada: Reeletrizando o Mundo de Edison ao Google), Carr examina o futuro da computação e suas implicações para os negócios e sociedade:

[...] símbolos falando com símbolos em símbolos. Os primeiros textos sobre a metafísica da Web, muitos escritos por pensadores associados ou influenciados pelos movimentos New Age pós 1960, são enriquecidos com uma perpassante sensação de libertação espiritual; eles descrevem a passagem para o mundo cibernético como um processo de libertação pessoal e comunal, uma jornada que nos liberta das amarras tradicionais sobre a nossa inteligência, nossas comunidades, nossos miseráveis físicos individuais. Nós nos tornamos livres flutuantes netizens (cidadanautas) em um âmbito mais iluminado, quase angélico. (CARR, 2005, p.1, tradução nossa).

Partindo desta provocação, o olhar do crítico cria profícuos debates transnacionais sobre o papel dos computadores em nossas vidas, em linguagem não acadêmica, com possibilidades abertas de diálogo enfatizadas pela formatação no seu concorrido blog Rough Type. No The amorality of Web 2.0 (A amoralidade da Web 2.0), post de 2005, desmistifica mitos criados pela indústria cultural em torno do conceito de Web 2.0, uma "Terra Prometida 'empacotada", em que somos descorporificados e transformados em pura linguagem. Da mesma forma orgânica com que se desenvolve o diálogo provocado por Carr, o conceito de Web 2.0 ou Web Social emergiu do desenvolvimento comunitário da Web, chamada por comparação, 1.0: por desenvolvimentos conceituais e tecnológicos, que conduziram às novas necessidades e à consequente criação de aplicativos para elas. Estes foram pragmaticamente focados nos aspectos sociais das comunidades de usuários empoderadas pelo uso consciente da informação organizada em conhecimento bottom-up. 
A Web Semântica, ao contrário, parte das reflexões de especialistas sobre a automação das ações agregadoras de informação realizadas por humanos. Um link hipertextual pode ligar tudo entre si, não reconhecendo hierarquias e discriminação entre categorias informacionais. Por meio de lógicas descritivas que conduzem a sistemas de ontologias, a criação de metalinguagens de recuperação na Web Semântica procura padrões, cria designs, automatiza para realizar complexidades.

O desenvolvimento natural e a progressiva separação de conteúdo e representação conduziram o sistema para a formação desta comunidade de pesquisadores que top-down passam a pensar soluções para os naturais problemas que emergem das novidades. Organizados, formam um Consórcio (World Wide Web Consortium - W3C), atualmente o centralizador da padronização, codificação de linguagens e protocolos de interoperabilidade.

\section{Web Semântica e a Web Social Semântica: algumas reflexões}

Neste momento, faz-se importante lembrar que, idealizada por Tim Berners-Lee, a Web Semântica pretende embutir inteligência e contexto na Web e possibilitar a melhor recuperação e uso da informação em uma rede de conhecimento interligado. Para tanto, propõe um novo modo de organizar os recursos informacionais na Web, com base na implantação de ferramentas tecnológicas e técnicas de representação do conhecimento, com o intuito de melhorar a recuperação desses recursos. A Web Semântica é assim considerada uma evolução, com uma nova forma de desenvolvimento e utilização da Web, baseada no uso de tecnologias que proporcionem um maior significado na Rede e que pode ser definida como:

[...] um conjunto de iniciativas, tecnológicas em sua maior parte, destinadas a criar uma futura World Wide Web na qual os computadores podem processar a informação, isto é, representá-la, gerenciá-la, como se os computadores possuíssem inteligência. (CODINA, 2003).

Tim Berners-Lee (2001), ao pronunciar a desde então repetida frase "A Web Semântica não é uma Web separada, mas uma extensão da atual", visualizava as oportunidades que a sistemática da Rede oferece à inteligência coletiva, potencializandoa pelo artifício da automação de uma linguagem controlada. Se a maioria dos conteúdos da Web (cuja propriedade essencial é a universalidade) atualmente é destinada à leitura por humanos e não para processamento de seus significados por computadores, o que se 
pretende com a Web Semântica é mudar essas proporções: fazer com que cada vez mais as informações possam ser decodificadas e inter-relacionadas automaticamente, pela criação de ambientes em que os softwares leiam tais codificações, cooperando com os usuários em função de capacitar o ser humano como coletividade.

De acordo com Berners-Lee, o poder efetivo da Web Semântica pode ser percebido pela capacidade que os agentes de softwares possuem em processar e trocar informações dispersas em vários repositórios (BERNERS-LEE; HENDLER; LASSILA, 2001). Isso ocorreria a partir da disponibilização de recursos marcados semanticamente, para que pudesse haver o entendimento pela parte dos agentes de softwares. O sonho daqueles que trabalham por uma Web Semântica é, portanto, potencializar computadores para esta hierarquização e discriminação, corrigindo o que é considerado uma limitação.

O seu maior desafio, segundo Faria e Girardi (2002), é:

[...] criar uma linguagem que seja capaz de expressar ao mesmo tempo o significado dos dados e definir regras para raciocinar sobre os mesmos, de forma a deduzir novos dados e regras e permitir que regras existentes em sistemas de conhecimento possam ser exportadas para a Web.

Automatizar a linguagem humana, entretanto, é uma tarefa que envolve complexidade, diálogo e multidisciplinaridade entre noções de arquitetura, design, (modelagem de ambientes informacionais), linguística (estruturas de representação), administração e economia e políticas (de informação, para citar apenas algumas das relações que necessitam de agenciamento no contexto da universalidade da Web). Os benefícios implícitos na palavra universalidade têm seu avesso nas barreiras quando o termo tangencia as incapacidades de discriminação (em menor ou maior grau) nos programas.

A Web Semântica conta, para a superação progressiva das barreiras acima mencionadas e a partir de inputs humanos, com várias ferramentas tecnológicas em sua arquitetura de implementação, tais como:

- Metadados: que proporcionam a necessária representação de um recurso informacional para sua posterior recuperação;

- Linguagem de marcação XML - eXtensible Markup Language: que possibilita uma melhor estruturação dos recursos e uma maior flexibilidade e extensibilidade para a representação e intercâmbio dos dados e metadados; 
- Arquitetura de metadados: mais especificamente a arquitetura de metadados RDF - Resource Description Framework, recomendada pela W3C para garantir a interoperabilidade dos dados em nível semântico, estrutural e sintático;

- Ontologias: que proporcionam a definição semântica dos dados representados pelos metadados em uma determinada comunidade de interesse;

- Agentes inteligentes: que proporcionarão uma busca e recuperação mais efetiva a partir do estabelecimento de regras e do acesso a coleções de recursos devidamente estruturados, representados e definidos semanticamente.

No entanto, é preciso que os agentes de softwares tenham acesso não somente às definições estabelecidas nas ontologias, mas também a uma coleção de recursos informacionais devidamente estruturados e representados.

A Web Semântica e a Web Social Semântica se encontram, nesse contexto, como possibilidades em construção para realizações pautadas no conceito de que as redes são compostas por nós conectados ou links, como as ilhas são ligadas por pontes, os mercados por rotas comerciais, os computadores por linhas telefônicas e pessoas por relacionamentos.

Tal contexto exige a compreensão dos apontamentos de Peter Morville (2005) sobre as ontologias, as taxonomias e as folksonomias como estruturas não mutuamente excludentes, mas com uma utilização que depende do contexto informacional. Em algumas situações, tais como a das intranets e a das redes de conhecimentos, uma ecologia de metadados híbridos que combine elementos das ontologias, das taxonomias e das folksonomias pode ser ideal, pois resulta em uma sinergia potencial estendida. Desta maneira, aplicações da plataforma Web 2.0 ou Web Social - como a Wikipedia, a blogosfera e o FaceBook, por exemplo - conhecidas pela produção constante de dados e informação online, devido justamente aos efeitos de sua correlação em rede, seriam beneficiadas por outras aplicações emergentes de uma já denominada Web 3.0. Estas, potencializadas por tecnologias semânticas (como RDF e OWL), ofereceriam as capacidades adicionais de organização de dados, interoperabilidade e recuperação de informação que atualmente são os fatores de fragilidade na Rede.

Em decorrência, Web Social Semântica (W2S), termo cunhado por Manuel Zacklad e Jean-Pierre Cahier em 2003, para ser usado no campo do Trabalho Coorporativo com 
Computadores (Computer Supported Cooperative Work - CSCW), reúne tais propriedades: é a soma da participação e contribuição escalonada de agentes humanos da Web Social, (em um crescente geometricamente proporcional ao aumento da participação) com as tecnologias combinadas dos softwares sociais, desenvolvidos por especialistas.

As duas modalidades, a Web Social e a Web Semântica, complementam-se na medida em que aproximam geração e organização de conteúdos submetidos por aqueles que deverão se apropriar da informação. A utilização de recursos já apreendidos, e que fazem parte dos seus hábitos de arquivamento, como a etiquetagem (folksonomia) e os metadados básicos, é otimizada pelas mais sofisticadas tecnologias do saber da lógica semântica, para a customização, a filtragem e a reutilização dos dados.

O que acontece é a adição de uma inexplorada dimensão da representação do conhecimento até então: os valores das redes sociais dos criadores das etiquetas se auto-organizando organicamente. A Web Social Semântica pretende ser a visão complementar Semântica ao adicionar a visão do apropriador da informação, o que naturalmente só é possível por artifícios invisíveis das linguagens de descrição e ontologias estruturais anteriormente já inseridas nos programas da plataforma 2.0.

Ao conceito de recuperação de informação substantiva-se uma abertura às cooperações: cria-se idealisticamente uma recuperação da informação aberta, que amplia sua metodologia no modelo hipertópico. Juntas, as taxonomias, folksonomias e ontologias propiciam maiores capacidades de interoperabilidade em relação aos cruzamentos de domínios e ao compartilhamento de conhecimento, palavras tão referidas na história das Webs.

Apresenta-se então o destaque de Sáez Vaca na preocupação apontada por Illich (1974), de que as tecnologias não deveriam gerar nem senhores nem escravos e no questionamento de Marinoff (2006, p. 432): "são os computadores ferramentas digitais multifunções, que servem aos fins humanos ou somos nós ferramentas humanas multifunções e servimos de nós na rede digital?"

Na mesma direção, no capítulo 7 de Além da Internet: A Rede Universal Digital,6 o autor (SÁEZ VACAS, 2004) adere às considerações de Norman (1998, p.135) e reafirma que, como seres humanos, somos seres analógicos presos em armadilhas de um mundo digital: entidades biológicas, adaptativas, tolerantes, sensíveis, que estamos, entretanto,

\footnotetext{
${ }^{6}$ http://www.gsi.dit.upm.es/ fsaez/int//Red\%20Universal\%20Digital/index.html
} 
construindo uma realidade mediada por máquinas rígidas, inflexíveis, precisas, exigentes e intolerantes. Nossa preocupação soma-se à dos autores, pois na atualidade todos nós somos uma combinação de amos e escravos e alternamos o comando de nossos aparatos digitais com a obediência a eles. A solução para ao menos atenuar este problema deve ser uma humanização das máquinas, pelo menos no sentido de que estas se comuniquem com o ser humano em sua língua natural, acoplando-se aos seus sentidos humanos por meio de um desenho antropocêntrico da tecnologia.

Não caminharia justamente neste sentido a hibridez da Web Social Semântica?

\section{REFERÊNCIAS}

ANDERSON, B. R. Comunidades imaginarias. México: F.C.E., 1993.

BELKIN, N. The cognitive viewpoint in information science. Journal of Information Science. v.16, p.11-15, 1990.

BERNERS-LEE, T.; HENDER, J.; LASSILA, O. The semantic Web: a new form of Web content that is meaningful to computers will unleash a revolution of new possibilities. Scientific American, New York, may. 2001.

CARR, N. Does IT matter? information technology and the corrosion of competitive advantage. Boston: Harvard Business School Press, 2004.

. The amorality of Web 2.0. Rough Type, 2005. Disponível em:

<http://www.roughtype.com/>. Acesso em: 26 abr. 2009.

CODINA, L. La web semántica : una visión crítica. El profesional de la información. Barcelona, v. 12, n. 2, p. 149-152. 2003.

DELEUZE,G. Mil mesetas. Valencia: Pré-textos, 1988.

DREXLER, K. E. Hypertext publishing and the evolution of knowledge. Social Intelligence, v. 1, n. 2, p.87-120, 1991. (An edited version of a paper originally submitted to the Hypertext 87 conference.) Disponível em:

<http://edrexler.com/d/06/00/Hypertext/HPEK1.html\#anchor328155>. Acesso em: 10 maio 2009.

FARIA, C. G.; GIRARDI, R. Uma análise da Web Semântica e suas implicações no acesso a informação. 2002. Disponível em: <http://maae.deinf.ufma.br/ensino/ia/artigos/>. Acesso em: 13 jan. 2005.

FIELDING, R. T. Architectural styles and the design of network-based software architectures. 2000. University of California, Irvine. Dissertation (Doctor of Philosophy in Information and Computer Science). Disponível em:

<http://www.ics.uci.edu/ fielding/pubs/dissertation/top.htm>. Acesso em: 12 maio 2009. 
FUMERO, A.; ROCA, G. Redes Web 2.0.Fundación Orange, 2007. Disponível em: $<\mathrm{http}: / /$ www.fundacionorange.es/areas/25_publicaciones/WEB_DEF_COMPLETO.pdf>. Acesso em:12 jan. 2009.

GONZÁLEZ DE GÓMEZ, M.N. A informação: dos estoques às redes. Ciência da Informação, v. 24, n. 1, 1995.

HABERMAS, J. The theory of communicative action. Boston: Beacon Press, 1983.

HOSCHKA, P. CSCW research at GMD-FIR: from basic groupware to the Social Web. SIGGROUP Bulletin, v.19, n.2, p.5-9, Aug. 1998.

ILLICH, I. La convivencialidad. Barcelona: Ed. Barral, 1974.

JARA, C. J. A sustentabilidade do desenvolvimento local: um processo em construção. Brasília: Instituto Interamericano de Cooperação para Agricultura; Recife: Secretaria de Planejamento do Estado de Pernambuco - SEPLAN, 1998. 316p.

JORENTE, M.J. Tecnologias, mídias, criação e hipertextualidade na transformação de informação em conhecimento interativo. 2009. Tese (Doutorado em Ciência da Informação) - UNESP, Marília, 2009.

KREY, A. C. History and the social web: a collection of essays. Minneapolis: University of Minnesota, 1955.

LEVY, S. The trend spotter. In: Wired 13.10, October 2005. Disponível em:

<http://www.wired.com/wired/archive/13.10/oreilly.html>. Acesso em: 10 dez. 2007.

MARINOFF, L. EI ABC de la felicidad. Barcelona: Ediciones B, 2006.

McLUHAN, M. Os meios de comunicação como extensões do homem. Tradução de Décio Pignatari. São Paulo: Cultrix, 1974.

MORVILLE, P. Ambiente findability. Cambridge: O'Reilly, 2005. 204p.

NEEF, M. Empoderamento de comunidades e desenvolvimento alternativo. Pedagogia social, abr. 2003. Disponível em:

$<$ http://www.pedagogiasocial.com.br/_files/artigos_frame_arquivos/Artigos\%20do\%20site/ Artigos_002.pdf>. Acesso em: 08 jan. 2009.

NORMAN, Donald. The life cycle of a technology: why good products can fail, the personal computer is so complex, and information appliances are the solution. Cambridge, MA: MIT Press, 1998.

OASIS. OASIS XDI Wiki: ExampleXdiDocuments. 2006. Disponível em: <http://wiki.oasisopen.org/xdi/ExampleXdiDocuments\#head-

75c6d535a5a15e70cd85074dd3245ba831276d91 >. Acesso em: 06 maio 2009.

REED, D. et al. The social Web: creating an open Social Network with XDI, 2004.

Disponível em: <http://journal.planetwork.net/article.php?lab=reed0704>. Acesso em: 15 fev. 2009.

SÁEZ VACAS, F. Más allá de internet: la Red Universal Digital. Editorial Centro de Estudios Ramón Areces 2004. 392p. Disponível em: 
<http://www.gsi.dit.upm.es/ fsaez/int//Red\%20Universal\%20Digital/index.html>. Acesso em: 15 mar. 2009.

. Noomorfosis digital. Publicado no blog Infotecnología, Empresa y Sociedad de Antonio Fumero. 23 de ago. 2006. 7p. Disponível em:

<http://antoniofumero.blogspot.com/2006/08/noomorfosis-digital.html>. Acesso em: 12 mar. 2009.

Sociotecnología de la información: teoría de la complejidad sociotécnica de las tecnologías de la información. 2008. 18p. Disponível em:

<http://www.gsi.dit.upm.es/ fsaez/sociotecnologia.html>. Acesso em: 15 mar. 2009.

SÁEZ VACAS, F. Vida y sociedade en el Nuevo Entorno Tecnosocial. In: FUMERO, A.; ROCA, G., Redes Web 2.0. Fundación Orange, 2007. p. 96-122. Disponível em: $<$ http://www.fundacionorange.es/areas/25_publicaciones/WEB_DEF_COMPLETO.pdf>. Acesso em: 12 jan. 2009.

SANTOS, P. L. V. A. C. Redes informacionais como ambiente colaborativo e de empoderamento: a catalogação em foco. In: GUIMARÃES, José Augusto Chaves; FUJITA, Mariângela Spotti Lopes (Org.). Ensino e pesquisa em Biblioteconomia no Brasil: a emergência de um novo olhar. São Paulo: Cultura Acadêmica, 2008, p. 155-171.

.; VIDOTTI, S. A. B. G. Perspectivismo e tecnologias de informação e comunicação: acréscimos à Ciência da Informação? DataGramaZero: Revista de Ciência da Informação, v.10, n.3, jun. 2009.

SHIRKY, C. Social software and the politics of groups. [S.I.], 2003. Publicado primeiramente na lista de discussão Networks, Economics, and Culture, 2003. Disponível em: <http://shirky.com/writings/group_politics.html>. Acesso em: 10 maio 2009.

WERSIG, G.; WINDEL, G. Information Science needs a theory 'Information Action' Social Sciences. Information Studies. v.5, p.11-23, 1985.

\title{
Title
}

When the Webs converge: social and semantics - turning real the promise of a vision?

\begin{abstract}
Information Science requests definitions and redefinitions of methods to value and highlight the important aspects of the dissemination relations, retrieval and knowledge compartment when the re-articulation of social relations and production occurs around Information Technology and Communication Technologies (ICTs). The text presents new approaches of interdisciplinary and transdisciplinary research and dialogue within various fields of knowledge networking. It presents a theory/model by Sáez Vacas (2002) to define and study the techno New Environment (NET) in a systemic perspective of the extremely complex, digital infrastructure, the Universal Digital Network (RUD), that provide technological tools for nontechnical users. The present moment offers the possibility of collaborative construction of knowledge marked by collective intelligence, social equity of information transfering, considering social networks as potential anthropological environments. Social and technological advances create new dynamics of the network and define the emergence of Web 2.0, Social Web or Web NG (new generation of users, the digital natives), Social Semantic Web and Semantic Web.
\end{abstract}




\section{Keywords}

Information and Technology. Web 2.0. Semantic Web. Social Web. Semantic Social Web.

\section{Título}

Cuándo las Webs se encuentran: social y semántica - promesa de una visión realizada?

\section{Resumen}

La Ciencia de la Información pide definiciones y redefiniciones de métodos que valoren y destaquen los aspectos importantes de las relaciones de diseminación, de recuperación y de compartimiento de los conocimientos cuando ocurre la rearticulación de las relaciones sociales y de producción en torno a las Tecnologías de Información y Comunicación (TICs). Se recoge en las interdisciplinaridades y transdisciplinaridades investigar y dialogar con los distintos campos del conocimiento en red. Se presenta el modelo-teoría de Sáez Vacas (2002) para definir y estudiar el Nuevo Entorno Tecnosocial (N.E.T) según una perspectiva sistémica de la infraestructura digital extremadamente compleja, la Red Universal Digital (R.U.D.) con instrumentos tecnológicos para usuarios no técnicos. El momento actual ofrece la posibilidad de construcción de un saber colaborativo marcado por la inteligencia colectiva, en acciones sociales de transferencia de información, bajo la mirada de las redes sociales como un ambiente antropológico de posibilidades. Avances sociales y tecnológicos crean una nueva dinámica de la Red y definen la aparición de la Web 2.0, Web Social o Web NG (Nueva Generación de usuarios, los nativos digitales), Web Semántica y Web Social Semántica.

\section{Palabras clave}

Información y Tecnología. Web 2.0. Web Social. Web Semántica. Web Social Semántica.

Recebido em: 27.05.2009

Aceito em: 31.08.2009 